direct and conclusive evidence that these cells contract in response to oxytocin (the essence of the neuro-hormonal theory) remains to be provided.

The clinical aspect of lactation was introduced by Dr. A. Ginglinger (France) in a paper in which he discussed factors other than hormonal ones which adversely affect lactation in women. Here the stress was mainly on social pressures arising from contemporary conditions of civilization which tend to make many women reluctant to suckle their infants. The lively discussion which followed ranged widely and touched also on the related subject of adverse psychological factors which, by interfering with the neurohormonal reflex concerned in milk ejection, could seriously prejudice the success of lactation. The colloquium concluded with a paper of unusual interest by Dr. R. Deanesly and Dr. A. S. Parkes (Great Britain), who have collected reports by anthropologists, medical missionaries and other such observers, of methods practised among primitive peoples, for the purpose of inducing lactation in non-parturient women or improving lactation already, established. A common feature of most of these reports is the administration to the subject of certain plants or plant preparations often accompanied by manipulation of the nipples to mimic the suckling stimulus. Though well-authenticated confirmation of the galactogogue properties of such plant preparations is entirely lacking, nevertheless the authors considered that the reports are sufficiently consistent and their sources so widespread as to justify a wellcontrolled investigation of the whole question by an expedition composed of experts qualified in the relevant scientific fields.

S. J. FoLLEY

\section{INDUSTRIAL RADIOLOGY}

THE Summer Meeting and Exhibition arranged by the Industrial Radiology Group of the Institute of Physics was held during the last week of July in the New Horticultural Hall, London. Accommodation was provided by the organising committee of the Technical Exhibition of the International Congress of Radiology held in London during the same period.

The meeting opened on July 25 with a paper by Mr. E. E. Smith (National Physical Laboratory) on "Industrial Aspects of Radiological Measurements". He discussed the changes likely to be made in funda. mental units such as the 'röntgen' and the 'curie', and particularly how these will affect the industrial radiologist. When the recommendations of the International Congress are published, it is hoped to arrange a further meeting of the Group to discuss this subject.

On July 26 a paper was given by Dr. W. P. Grove (Radiochemical Centre, Amersham) on the "Handling and Transport of Gamma-Ray Sources for Radiography". Dr. Grove sketched the requirements for protecting both human beings and photographic materials from possible damage by gamma-radiation. Regulations have been drawn up, in the light of these requirements, regarding the use of public transport for the carriage of materials emitting gammaradiation.

Mr. B. N. Clack (Radiochemical Centre, Amersham) spoke on "Natural and Artificial Sources of Gamma Radiation". After sketching the requirements for radiography of various materials, he indicated to what extent these have been achieved with both natural materials and with radioisotopes produced in the pile, and went on to show the trend in design of exposure containers. The lecture was illustrated by a number of slides of the plant at Amersham for making radiographic sources containing radon by adsorbing the gas on a small grain of charcoal in the manner originated by Dawson. Mr. Clack stated that radon is finding considerable application, because of the excellent quality of the radiographs obtained with it.

One session which proved of great interest was a symposium on industrial radiology in countries outside Britain. This opened with a paper by Dr. E. Dale-Trout (U.S.A.) on the "Characteristics of Lead Screens for Industrial Radiology", which contained much new and interesting information. A. Menetrier (Babcock and Wilcox, France) described the radiographic examination in France of welds in pressure vessels, and mentioned the general use of rod-type $X$-ray tubes placed inside the vessels for the examination of circumferential seams. He said that radiographic examination has enabled high-tensile steel to be used for welded tanks for the transportation of liquefied gases, thus enabling the weight to be reduced to one half. R. P. Barbotin (Kodak-Pathé, France) spoke of post-war difficulties, but said that rapid progress is now being made, and a high standard of radiographic technique can be ensured by the use of high-contrast fine-grain film. D. J. Binkhorst (Rontgen Technische Dienst, Holland) demonstrated a very convenient pack containing reference sets of penetrameter radiographs and comparative density films for use by inspectors when viewing radiographs. Mr. A. Junghem (Sweden) described the work of the Central Institute of Radiology founded in Stockholm in 1937. He maintained that radiographic quality control need not be more expensive than mechanical testing, and said that it is proposed shortly in Sweden to substitute 'spot checks' by X-ray examination of structural welds in place of the usual routine mechanical tests. K. Koren (Norway) announced the formation about twelve months ago of a Central Institute in Norway for weld radiography; the chief application of industrial radiology in Norway is in the examination of pipe welds in hydroelectric plant. H. Vinter (Denmark), director of the Akademiet for de Technische Videns Kaber in Copenhagen, spoke of the work of this newly established Institute. He showed illustrations of a very unorthodox portable X-ray equipment, every part of which can be carried by one man and passed down the hatchway of a ship. The equipment was shown in use in various simple arrangements for the examination of ship welds. The design requirements of the equipment were that there should be no high-tension cables, no external coolers, and that it should be weatherproof; in fact, the control table will operate when immersed in water. The larger of two models operated at a maximum voltage of $170 \mathrm{kV}$. with a tube current of 2 milliamp.

At another meeting there was a symposium on the subject "What is the Use of Industrial Radiology ?" The meeting opened with a thoughtful contribution by Mr. B. R. Byrne (Railway Executive, Southern Region), who emphasized the great care necessary by industrial organisations in the selection of radiographic equipment, in the training of operators and in the choice of consultants. Mr. G. T. Harris (Wm. Jessop and Sons, Ltd.) said that far more work is needed to correlate radiographic findings with the mechanical strength of the material, and to compare 
various methods of non-destructive testing. He gave results of tests on turbine disk forgings of austenitic steel which showed satisfactory agreement between radiography, ultrasonic examination and tensile tests. Mr. J. C. Rockley (A.I.D. Test House, Harefield) referred to the well-known radiographic inspection of stressed castings for aircraft and described three other useful applications : detection of internal corrosion in aircraft fuel tanks ; detection of faulty assembly of pitot pressure heads; detection of metallurgical defects in cartridge cases.

Dr. H. Harris (Babcock and Wilcox) stressed that the proper function of the radiographic examination of welded joints in pressure vessels is not so much to prove the acceptability of a particular weld as to correlate the weld with the test welds which are subject to mechanical tests. The greatest value of radiography is in developing welding processes rather than as a routine method of inspection.

Mr. H. S. Peiser (Hadfields, Ltd.) said that the fact that his firm is spending some $£ 15,000$ on a new radiological laboratory is evidence of its belief in the value of industrial radiology. Mr. J. F. Hinsley (Edgar Allen and Co., Ltd.) spoke of the expansion of the radiological facilities of the firm which he represents. He referred to a very important radiographic examination of castings for the housing of electric traction motors, etc., and described the methods of repairing surface irregularities by welding. Mr. S. M. Reisser (Murex, Ltd.) stressed the importance and the difficulty of attaining uniformity in radiographic interpretation, and emphasized that full details of radiographic technique are essential for accurate interpretation.

An exhibition of industrial radiology arranged by Dr. D. H. Follett (Science Museum) was held throughout the week. Some fifty exhibitors contributed to it, including the British Standards Institution, Mr. F. I. G. Rawlins of the National Gallery (who demonstrated the radiography of oil paintings), and Dr. C. Moss of the British Museum (who showed archæological radiographs). There was also a variety of radiographs illustrating the use of radio isotopes, auto-radiography, flash radiography, and radiography with a 1.4-MeV. synchrotron. There were several photographs of radiographic equipment, including one of an X-ray laboratory in a railway coach, shown by Mr. Knights and Mr. Dearden of the Railway Executive, Midland Region. Apparatus was shown for the radiographic examination of pipe welds. One piece of apparatus exhibited enabled the level of mercury in a steel manometer tube (made necessary because the pressure is too great for glass to withstand) to be read by sending a beam of gamma-rays through the tube and detecting it with an ionization chamber and cathode-ray tube. The Armament Research Establishment of the Ministry of Supply exhibited a new type of sensitive penetrameter devised for use in the radiographic examination of welded joints. The same Establishment also exhibited a container for use in gamma-radiography, made from tungsten alloy to minimize the transmitted radiation. The operator can allow gamma-rays to emerge when required by an automatically released 'stopper', while remaining shielded from the radiation himself. It is suitable for sources up to 1 curie in strength, and the source is automatically returned to a safe position when the container is raised on completion of an exposure. One of the radiographs, taken with an exposure of one-millionth of a second, showed a bullet travelling through water.

\section{PLANT BREEDING IN GREAT BRITAIN}

$T$ HE fourth annual conference of British plant breeders was held at the Scottish Plant Breeding Station, Corstorphine, Edinburgh, dur ing August 3-4 and was attended by representatives of the John Innes Horticultural Institution, Bayfordbury; the Plant Breeding Institute, Cambridge; the Welsh Plant Breeding Station, Aberystwyth; the Plant Breeding Division, Ministry of Agriculture, Belfast; the National Vegetable Research Station, Wellesbourne; the Scottish Society for Research in Plant Breeding, Edinburgh; the Department of Agriculture for Scotland; and the Agricultural Research Council. At the conclusion of the conference, the invitation of Dr. C. D. Darlington, director of the John Innes Horticultural Institution, Bayfordbury, to hold the next conference at Bayfordbury in 1952 was accepted.

Sir John H. Milne Home welcomed the visitors on behalf of the board of directors of the Scottish Society for Research in Plant Breeding, and Sir Patrick Laird on behalf of the Department of Agriculture for Scotland. Mr. William Robb, director of research of the Scottish Society for Research in Plant Breeding, opened the proceedings by giving an account of the origin and organization of the Society, and the first morning of the conference was devoted to giving in turn an outline of the work of the various departments-cereal breeding by Mr. Robb, herbage breeding by Dr. J. W. Gregor, potato breeding by Dr. William Black, potato virus diseases investigations by Dr. G. Cockerham, and swede and sugar beet breeding by Dr. V. McM. Davey. The afternoon of August 3 and the morning and afternoon of August 4 were divided into five sessions, in which the party visited in turn the experimental plots of these departments, spending the morning of August 4 at the Potato Breeding Sub-Station at Boghall.

Cereals and Beans. In the breeding work with oats, the pedigree method of breeding has been mainly followed, but the 'bulk' method is now being tried. The main problems are to breed by hybridization and selection oats which are : productive, disease-resistant varieties highly resistant to lodging and having good quality milling grain which possesses resistance to germination at harvest time; hardy, early-ripening types for upland areas; and varieties showing a higher degree of tolerance of alkaline soil conditions than most standard varieties at present in cultivation.

A large number of unfixed hybrids were seen in plots in various stages of development, ranging from the first to the sixth generation. Attention was directed to various selections to illustrate the progress made in breeding for shorter straw and resistance to lodging, early-ripening types for upland areas, selections resistant to sprouting in the ear, and a selection adapted to alkaline soil.

Interest was shown in a number of transgressive segregates which illustrated wide genetical differences in length of straw and type of ear. The methods followed in testing the Society's new varieties at the Station, and at other centres in various parts of the country in co-operation with the three agricultural colleges in Scotland, were referred to, and the systerm followed in putting the Society's new varieties into commerce was outlined.

Mr. D. Cameron and Mr. H. D. Garvin demonstrated the work being done at the Station with barley and 